\title{
¿QUÉ SE ENTIENDE POR "SIETE REINOS O REYES” EN APOCALIPSIS 17:10?
}

\author{
ERIK Jiménez Milla \\ DOCENTE DE LA FACULTAD DE TEOLOGIA - UPEU
}

\section{Introducción}

Cuando se escucha cada interpretación de este pasaje, se hace necesario considerar la Biblia como principal eje de estos símbolos. Muchos sin tener la mínima consideración a los principios de interpretación bíblica, han aventurado sus opiniones a querer identificar a "personas" o "individuos" en este pasaje.

En este artículo, el objetivo es mostrar las conexiones intertextuales del término "montes" y "reyes", para evaluar cada interpretación de este pasaje a la luz de la propia Palabra de Dios.

Se considera como una hipótesis válida el hecho de que en el mismo capítulo 17 , se usa ya el lenguaje metafórico desde el primer versículo. Este elemento de la naturaleza que se usa son las "aguas", y según el mismo capítulo representan a pueblos, multitudes, naciones y lenguas (Ap 17:15). Por eso se cree que los montes no deben ser interpretados en forma literal. Si hay un elemento de la naturaleza que no es interpretado como tal, entonces los "montes" y "reyes" tienen que expresar o ser un símbolo. Hay que dar una mirada entonces a la Biblia y ver si tiene razón esta presuposición.

\section{Montes}

El vocablo op $\eta$ que traducido es "montes", y su raíz opo $\varsigma-$ montaña. Esta palabra dentro de la frase Ai 'è̀ta. kef al ai . è̀ta. orh e $\operatorname{sin~"las~siete~cabezas~son~siete~montes",~tiene~a~lo~largo~de~la~histo-~}$ ria un sinnúmero de interpretaciones.

La primera, la preterista, es aplicada a menudo a Roma en el 
mundo antiguo, ya que fue, ésta, construida sobre siete colinas. ${ }^{1}$ La ciudad comenzó con una amalgama de grupos que vivían en las siete colinas (Aventino, Celio, Capitolino, Equiline, Palatino, Quirinal, Viminal), y durante el reinado de Domiciano era celebrado un festival denominado el septimontium. La profecía explica que la "mujer" se sienta sobre estas siete cabezas y éstas son "montes", significa que está entronizada en Roma, y por lo tanto, la gobierna. ${ }^{2}$ Sin embargo, ¿será éste el verdadero significado de esta palabra?

orh en un contexto escatológico, se lo ve desde la perspectiva de Lucas 3: 4 e Isaías 40: 3. En este sentido, los montes pueden tomar un matiz de poderío político, reino o poder nacional (Jer 51: 25; Dan 2: 44). En relación con la predicación de arrepentimiento de Juan el Bautista, la "nivelación" de las montañas que prepararía el camino para el Mesías, se debía entender como el establecimiento de un reino, el reino de Cristo.

Según Apocalipsis 8: 8, la montaña caracteriza el tamaño de una estrella que cae en el mar. En el 14:1, Sión es el lugar de seguridad donde se reúne el pueblo de Dios. En Hebreos 12: 22 Ziww opos es una designación de la nueva alianza, refiriéndose en forma simbólica al monte de Sión. ${ }^{3}$

Un texto que ayuda en el entendimiento de este símbolo, está dado en Jeremías 51:24-26, en donde se explica el juicio al Imperio Babilónico. Dice:

"Y pagaré a Babilonia y a todos los habitantes de Caldea todo el mal que han hecho en Sión delante de vuestros ojos-declara el Señor. He aquí, yo estoy contra ti, monte destructor, que destruyes toda la tierra - declara el Señor. Extenderé mi mano contra ti, te haré rodar desde las peñas y te reduciré a monte quemado. Y no tomarán de ti piedra angular, ni piedra para cimientos, pues desolación eterna serás-declara el Señor”.

${ }^{1}$ Grant R. Osborne, "Revelation", de Baker Exegetical Commentary on the New Testament (Grand Rapids, MI: Baker Academic, 2002), 617. Véase Cicerón, Att. 6.5; Plinio, Nat. Hist. 3.66-67, et al.; ver Swete 1911: 220 para otros. En adelante RBECNT.

${ }^{2} R B E C N T, 617$.

${ }^{3}$ Ibíd. 
Esta expresión es netamente simbólica y profética. Daniel también da mayor luz a este símbolo. En el contexto de los grandes imperios mundiales, encontramos en Daniel 2: 35.

"Entonces fueron desmenuzados, todos a la vez, el hierro, el barro, el bronce, la plata y el oro; quedaron como el tamo de las eras en verano, y el viento se los llevó sin que quedara rastro alguno de ellos. Y la piedra que había golpeado la estatua se convirtió en un gran monte que llenó toda la tierra".

Entonces este monte es el verdadero reino que se establecerá en la tierra. Más adelante, ya en la interpretación de esta visión, el libro de Daniel presenta una explicación clara de este símbolo, dice así "En los días de estos reyes, el Dios del cielo levantará un reino que jamás será destruido, y este reino no será entregado a otro pueblo; desmenuzará y pondrá fin a todos aquellos reinos, y él permanecerá para siempre, tal como viste que una piedra fue cortada del monte sin ayuda de manos y que desmenuzó el hierro, el bronce, el barro, la plata y el oro" (Dn 2: 44-45a).

En el contexto profético un monte, o elevación prominente en la superficie de la tierra, es una de las imágenes bíblicas comunes para representar a un reino, dominio real, imperio o autoridad establecida. Otros textos lo confirman. ${ }^{4}$

En ese sentido, la posición que los montes se refieren a Roma no puede ser correcta, porque la palabra "montes" está en un contexto simbólico, no literal. Además, el día que se quiera aceptar una parte literal y otra simbólica, el investigador se confundirá y fallará en su intento de descifrar la alegoría. Este asunto de los montes está en un libro netamente simbólico y tiene que ser entendido así.

El hecho de que la mujer se sienta sobre las siete montañas, es una antítesis de la mujer de Apocalipsis 12, la mujer está parada con la luna debajo de sus pies. La luna es símbolo de la Biblia, base de las creencias y accionar de la mujer. Ésta no tiene luz propia y refleja la luz del sol, la Biblia no tiene poderes sortilégicos en sí misma, sino refleja la luz de Cristo al que la lee y estudia. En esta consideración, la mujer de Apocalipsis 17 está sentada o tiene como base las creencias o enseñanzas

${ }^{4}$ Véase Salmos 2: 6; 7: 30; 135:21: Isaías 2: 2; 8: 18; Ezequiel 35: 3; Joel 3: 21; Miqueas 4: 2; Zacarías 4: 7; Hebreos 12: 22; Apocalipsis 14: 1; 21: 10. 
milenarias de todos los reinos que Satanás ha dirigido. Esta consideración lleva a la comprensión natural de que siete montañas constituyen los reinos históricos que han marcado las falsas enseñanzas de la Babilonia. Hay una condicionalidad natural de la Iglesia a las enseñanzas de estos siete reinos. Lange lo dice así: "A través del absolutismo de las monarquías del mundo, la mujer está continuamente atraída más y más al camino paralelo de jerarquización y su carácter se vuelve más y más corrupto". 5

En la historia general de la bestia y la mujer, el ángel le da a Juan la exposición histórica de los reinos del mundo, cada punto central en el tiempo. Por eso la declaración cinco reyes han caído, desde el punto de vista de reinos, tendrá que ver con imperios que han estado en el pasado.

La identificación de los siete montes con Roma se deriva de una hermenéutica que interpreta la Biblia bajo la luz de un ambiente histórico determinado, en lugar de interpretar el ambiente histórico a la luz de la Biblia. Esto se debe a que algunos intérpretes han asumido que la profecía revelada a través de Juan fue escrita exclusivamente para los contemporáneos de Juan y que éstos deberían entenderla con toda claridad. Aceptar tal idea equivale a pasar por alto pasajes como Daniel 12: 4, 9; 1 Pedro 1: 10-12. La profecía bíblica no siempre fue comprendida por quienes originalmente la escribieron".

En conclusión, Apocalipsis contrasta el Monte de Dios (Ap 14: $1 ; 21: 10)$, se reúne escatológicamente con su pueblo, con los montes o reinos que quisieron imponer su dominio en el mundo $\mathrm{y}$, aunque no lo quisieron tendrán su final. El tema de los montes representa reinos o imperios que han gobernado al mundo, mas no individuos. Es un asunto muy serio, no es extraño que muchos comentaristas intenten hacer creer que se trata de individuos.

\section{Reyes}

El término $\beta \alpha \sigma \lambda \lambda \varepsilon i \varsigma$ (reyes) tiene que ser entendido también como un símbolo profético. Para ello hay que ver cuál es la relación de

${ }_{5}^{5}$ John Peter Lange, Philip Schaff y Evelina Moore, A Commentary on the Holy Scriptures: Revelation (Bellingham, WA: Logos Research Systems, Inc, 2008), 314.

${ }^{6}$ Carballosa, Apocalipsis, 334. 
este término en otras partes de la Biblia.

En un primer sentido está relacionado con gobernantes o cabezas de reinos. Esto ocurre especialmente en Pablo y en el Apocalipsis. Se utiliza en referencia: a) Dios (Ap 11:17; 19:6. Como en 1 Co 4: 8; Lc 19: 14, 27), b) Cristo (1 Co 15: 25; Ap 11: 15; Lc 1:33), c) el dominio de la muerte, el pecado, o la gracia (Ro 5:14, 17, 21; 6:12), d) los cristianos como gobernantes (Ap 5:10; 20:4, 6, 22:5; Ro 5:17; 1 Co 4:8), y e) los gobernantes seculares (Mt 2:22, Lc 19:14, 27, 1 Tit 6:15). ${ }^{7}$

B $\alpha \sigma \imath \lambda \varepsilon u ́ \varsigma$, también se aplica en el NT a los hombres como dioses (o dios) y para los seres intermediarios entre Dios y el hombre. Desde el punto de vista de la teología bíblica, es un hecho importante que en el NT, en estrecha dependencia del AT y el uso de los judíos y en pleno acuerdo con él, Dios, así como Cristo (el Mesías Jesús) llevan este títu10. ${ }^{8}$ Por eso, "Cuando Jesús estuvo ante el gobernador, éste le preguntó: “Eres tú el Rey de los judíos?” Jesús le dijo: "Sí. Es como tú dices” (Mt 27:11). Y cuando estuvo en la cruz le decían: "Si tú eres el Rey de los judíos, sálvate a ti mismo"(Lc 23: 37), como si entendían que "rey" representaba a Dios mismo.

De Daniel 7:17 y 23, se sabe que los reyes representan a sus reinos. Aunque representan a sus reinos, el "reino" es mayor que el rey. El texto arameo de la traducción en el versículo 17 dice: "Estas bestias enormes, que son cuatro, son cuatro reyes que se levantarán de la tierra", se traduce en la LXX como "reinos" en armonía con el versículo $23,{ }^{9}$ que dice: "La cuarta bestia será un cuarto reino en la tierra, que será diferente de todos los otros reinos; devorará toda la tierra, la hollará y la desmenuzará". ${ }^{10}$ Esto es importante, porque para Daniel las cuatro bestias son interpretadas como cuatro reinos o cuatro reyes. Considerando que Babilonia no sólo tuvo a Nabucodonosor como rey, sino que

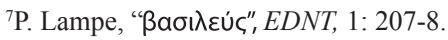

${ }^{8}$ Karl Ludwig Schmidt, TDNT, 1: 576.

${ }^{9}$ Simon J. Kistemaker y William Hendriksen, New Testament Commentary, Exposition of the Book of Revelation: Accompanying Biblical Text Is Author's Translation (Grand Rapids, MI: Baker Book House, 1953-2001), 20: 472.

${ }^{10}$ Henry Barclay Swete, ed., The Apocalypse of St. John, 2da ed. (New York: The Macmillan company, 1907), 217. 
hubieron otros reyes más que gobernaron en ese reino, es que se puede ir entendiendo que para el lenguaje profético no es muy importante el "individuo" sino el reino.

Esta concepción simbólica de esta expresión "reyes", aunque tiene aparentemente el mismo significado de los montes, describe a quienes representan o lideran a la bestia. En el pasado fueron los reyes quienes ejercían la autoridad del reino. Lógicamente en el marco de una presunción de autoridad divina, es importante esta consideración. No obstante, no hay que dejar de tomar en cuenta que los reyes, son el resultado de la interpretación de los diez cuernos. Estos cuernos representan según la Biblia, la manifestación del poder de la Bestia, la fuerza de aquellos que en determinado momento la representan

Aparentemente frente a este símbolo, no es la importancia de determinar a un número de reyes importantes, sino que la palabra rey simboliza la forma visible de un reino. Determina que ese líder visible siempre tendrá la prerrogativa de un rey del pasado. En otras palabras, es el reino la descripción histórica de esta palabra. El accionar de este reino o imperio siempre lo tendría un ser humano que presuma creerse rey de reyes, asumiendo el papel blasfémico de la mujer.

Entonces, los siete reyes no tienen que ser identificados en siete individuos, sino en unidad con las siete montañas. Así fue en el pasado, Daniel le dijo a Nabucodonosor, "tú eres la cabeza de oro" (Dn 2: 38c). Sin embargo, como ya se dijo, no fue Nabucodonosor el único rey del imperio, sino que en ese momento de la historia representaba el imperio de turno. Entonces "reyes" dice que en todos los tiempos de los siete imperios mundiales, sus reyes o representantes ejemplificarán los principios que tienen, y los evidenciarán en el reclamo constante de adoración personal.

\section{Conclusión}

La gran mayoría de eruditos de la escuela historicista, Kenneth A. Strand, Louis Were, C.M. Maxwell y otros estudiosos, respetando lo que la Biblia enseña acerca de estos símbolos determinan a las siete 
cabezas y los siete montes, como imperios y no a reyes específicos. ${ }^{11}$ Por esta razón, las interpretaciones que presentan a emperadores o papas tendrían que revisar el trasfondo profético descrito en el mismo Apocalipsis y en Daniel. Justo fue ése el objetivo de esta sección.

La pregunta que se hace es ¿interpreta Daniel en las profecías a individuos? Si interpretamos todo el sentido profético bajo una persona o individuo, se estaría estableciendo que un día el mundo entero caería de rodillas en adoración de un ser humano que toma atribuciones divinas. Se estaría pretendiendo que el objetivo de Satanás sería lograr que el mundo dé la espalda a Dios y adoren a un hombre-anticristo. Las profecías son determinantes, el pretender ser Dios del anticristo, no hace que éste anule a Jesús, por eso el anticristo sigue y seguirá mostrando a Jesucristo como su meta, para que el mundo siga confiando que sus enseñanzas son de procedencia divina. Por eso no importa el individuo, cualquiera que represente este poder en cualquier momento de la historia, seguirá los principios de rebelión ya establecidos y desenmascarados por la Palabra.

Apocalipsis 17: 9 dice que las siete cabezas de la bestia son siete montes y siete reyes. La clave para no desviarse al querer encontrar los nombres de los montes lo da el mismo capítulo, cuando el ángel interpreta un elemento de la naturaleza en forma simbólica. Las aguas son naciones, pueblos, muchedumbre. Esto determina, entonces, que cualquier otro elemento de la naturaleza, no tiene que ser interpretado en forma literal, sino simbólica.

En ese sentido, Juan escribe la descripción del futuro de los siete reinos o imperios, desde el uso del símbolo "monte" y "rey" que toda la Biblia ya lo había explicado. Aquellos que intentan poner el nombre de "papas" o "personajes" malvados en el futuro para identificar a estos "reyes", salen del verdadero sentido del pasaje, y su interpretación adolecerá de seriedad bíblica y se irá al campo de la especulación. Detrás de todas estas interpretaciones atemorizantes, hay escondidos propósitos satánicos, que intentan sacar a Daniel y Apocalipsis de su verdadero contexto.

En conclusión, los "montes" son las montañas, que cuando son mencionados por algún profeta, lo hace como símbolo de las potencias

${ }^{11}$ LaRondelle, Las Profecias del fin, 418. 
mundiales. ${ }^{12}$ La naturaleza del poder de estos imperios y reinos, es el poder político y religioso. Tomando este símbolo, Jesús establecerá su reino, como lo escribe la profecía de Daniel 2: 35. Ese monte es el reino eterno de Dios en esta tierra. Y cuando se establezca este imperio no habrán "diez reyes" sino sólo uno, es el "Rey de reyes y Señor de señores" viniendo a esta tierra.

${ }^{12}$ Lawrence O. Richards, The Bible Readers Companion, electronic ed. (Wheaton: Victor Books, 1991; Published in electronic form by Logos Research Systems, 1996), 922. 